\title{
Erratum to: Contrasting arm elevation angles \\ of multi- and two-armed sea urchin echinoplutei supports Grünbaum and Strathmann's hydromechanical model
}

\author{
Natalie A. Soars • Maria Byrne
}

Published online: 29 March 2015

(C) Springer-Verlag Berlin Heidelberg 2015

Erratum to: Marine Biology (2015) 162: 607-616

DOI 10.1007/s00227-014-2608-2

The authors would like to publish an erratum to correct the formatting error in Table 2 which incorrectly represented the results of the Tukey's HSD test. The correct version of the table is given below:

Table 2 ANOVA of postoral and posterodorsal arm angle data from 38 species with multi-armed larvae at different stages (arm numbers)

\begin{tabular}{llrrrr}
\hline & SS & $d f$ & MS & \multicolumn{1}{c}{$F$} & $p$ \\
\hline ANOVA PO arms & & & & & \\
Arm number & 1425 & 4 & 356 & 7.284 & 0.000 \\
Error & 6262 & 128 & 49 & & \\
Tukey's HSD & $(4,2,6)>10$ & & & & \\
ANOVA PD arms & & & & & \\
Arm number & 3124 & 2 & 1562 & 9.318 & 0.000 \\
Error & 11,902 & 71 & 168 & & \\
Tukey's HSD & $8>10$ & & & & \\
\hline
\end{tabular}

The online version of the original article can be found under doi:10.1007/s00227-014-2608-2.

N. A. Soars

School of Biological Sciences, University of Sydney, Sydney,

NSW 2006, Australia

M. Byrne $(\square)$

Schools of Medical and Biological Sciences, University

of Sydney, Sydney, NSW 2006, Australia

e-mail: mbyrne@anatomy.usyd.edu.au 